\title{
Supermodels and disease: insights from the HHT mice
}

\section{Claire L. Shovlin}

Respiratory Medicine, Imperial College School of Medicine, National Heart and Lung Institute, Hammersmith Hospital, Du Cane Road, London W12 0NN, United Kingdom. Phone: 44-181-383-3269; Fax: 44-181-743-9733; E-mail: c.shovlin@ic.ac.uk.

Why should the scientific and medical communities take note of the endoglin knockout mouse described by Bourdeau et al. in this issue of the JCI (1)? After all, it is not the first report of a mouse lacking this accessory protein for the superfamily of TGF- $\beta$ receptors (2).

As previously described (2), mice homozygous for an endoglin null allele exhibit an embryonic-lethal phenotype. The essential abnormality appears to be defective remodeling of the primary vascular plexus (3), resulting in abnormal yolk sac and embryonic blood vessel development. Bourdeau et al. (1) also carefully delineate the abnormalities in cardiac (particularly endocardial and cushion tissue mesenchyme) development, observed before the embryos succumb to the lethality of the vascular defect. Similar findings are to be reported elsewhere (4). These studies should prompt further delineation of roles for TGF- $\beta$ ligands and receptors (5) in the recruitment and differentiation of mural cells required to stabilise the immature vessel, as well as in the regulation of the epithelial-mesenchyme transformations required for these processes $(3,6)$.

More importantly, the key result of this paper (1) is that the endoglin het- erozygotes develop a phenotype remarkably similar to that of humans who are heterozygous for a null mutation in the endoglin gene: the vascular disorder Rendu-Osler-Weber syndrome (hereditary hemorrhagic telangiectasia, HHT) (7-9). (Note that HHT also results from mutations in $A L K-1$, the gene for activin receptor-like kinase 1 , a type I TGF- $\beta$ receptor [10]; and at least 1 further gene [ref. 11; and Wallace and Shovlin, manuscript in preparation]).

HHT is an autosomal dominant disorder usually recognised by nosebleeds, mucocutaneous telangiectasia, and, in later life, gastrointestinal bleeding. Some patients also develop arteriovenous malformations (AVMs) in the pulmonary, cerebral, and hepatic circulations (12-14). Despite what clinicians like to say, it is often good fortune that determines whether vascular lesions are of a nature and distribution that will respond to therapeutic efforts. Nasal and gastrointestinal bleeding are notoriously difficult to treat in HHT; most moderately affected patients rely on iron therapy and/or regular blood transfusions. The outlook for pulmonary AVM patients has been transformed with embolization therapies, but residual disease of varying signifi- cance remains in up to $60 \%$ of patients (14). The significant risks associated with intervention for cerebral AVMs mean that many patients are left untreated and at risk of intracerebral hemorrhage. In cases with severe hepatic involvement, there is now debate as to whether embolization therapy should even be attempted, or whether this complication is best treated by liver transplantation. Hence, we sorely need an animal model to assess potential therapeutic modalities.

The heterozygous mice described in this issue of the JCI (1) develop nosebleeds and cutaneous telangiectasia; interestingly, the ears are affected more commonly than in humans. From the data presented, it appears that some mice may also develop gastrointestinal and possibly pulmonary involvement. Should we be surprised or concerned that the abnormal vascular lesions develop predominantly in certain genetic backgrounds (129/Ola-rich) and only affect a proportion of heterozygous mice (Table 1 )? In fact, this mimics the human disease, in that particular lesions develop in only a subset of genetically-predisposed individuals, and manifestations vary between family members carrying the same endoglin

Table 1

The human and murine phenotypes

\begin{tabular}{|c|c|c|c|c|c|c|c|}
\hline Study group & Total & Nose bleeds & Onset & Telangiectasia & Onset & Visceral involvement & Reference \\
\hline \multicolumn{8}{|l|}{ Human, HHT patients } \\
\hline $\begin{array}{l}\text { French population, } \\
\text { mixed HHT genotype }\end{array}$ & 324 & 311 & $50 \%$ by 20 ys & 240 & $50 \%$ by 30 ys & $25 \%^{A}$ & 12 \\
\hline $\begin{array}{l}\text { UK population, } \\
\text { endoglin mutations }\end{array}$ & 30 & 29 & $73 \%$ by 10 ys & 27 & NS & $57 \%^{\mathrm{B}}$ & 8 \\
\hline \multicolumn{8}{|l|}{ Mouse, endoglin heterozygotes } \\
\hline $129 / \mathrm{Ola}>\mathrm{C} 57 \mathrm{BL} / 6$ & 10 & 3 & 2-12 weeks & 5 & $1-27$ weeks & & 1 \\
\hline C57BL/ $6>129 /$ Ola & 227 & 4 & 9-23 weeks & 14 & $8-25$ weeks & $\sim 1 \% \mathrm{c}$ & 1 \\
\hline C57BL/ 6 m 129/Ola & NS & 0 & & occasional $^{\mathrm{D}}$ & NS & & 4 \\
\hline $\mathrm{CD} 1>\mathrm{C} 57 \mathrm{BL} / 6 \mathrm{~m}$ 129/Ola & 51 & 0 & & 0 & & & 1 \\
\hline C57BL/ 6 m 129/SvJ & NS & 0 & & 0 & & & 2 \\
\hline
\end{tabular}

${ }^{A}$ Asymptomatic screening in other populations reveals true incidence to be higher (14). ${ }^{B}$ Ascertainment bias towards pulmonary AVMs. ${ }^{C}$ Breathing difficulties and internal

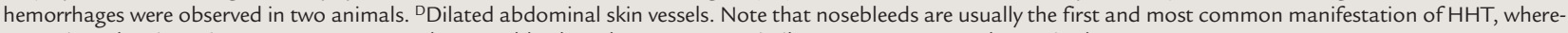
as murine telangiectasia were more common than nosebleeds and apparent at a similar age. NS, not stated; m, mixed. 
mutation (8). The mice become ever more appropriate HHT models.

The genetic background also appears to influence the phenotypes of homozygous endoglin null mice. Embryonic lethality occurs between 10-10.5 days in mice derived from 129/Ola embryonic stem (ES) cells bred into C57BL/ 6 animals $(1,4)$ but is delayed to 11.5 days in mice of $129 / \mathrm{SvJ}$ ES origin (2). We can anticipate studies delineating why the 129/Ola background renders endoglin null mice susceptible to earlier disease and leads to more pronounced disease in heterozygotes.

There are precedents for murine strain-dependent susceptibility to deficiencies in TGF- $\beta$ family members. The variation in the TGF- $\beta 1$ null phenotype $(15,16)$ may be particularly relevant, as endoglin can modulate TGF- $\beta 1$ signaling (17), probably by associating with the ligand-binding type II signaling receptor T $\beta$ RII (18). The endoglin null phenotype is similar to vascular defects seen in mice deficient for TGF- $\beta 1$ (19) and T $\beta$ RII (20), although these two mutant strains also exhibit defective hematopoiesis, which is observed in only one of the endoglin null mice models (4). Defective endothelial cell differentiation is also found in TGF- $\beta 1$ deficient mice. The NIH/Ola background rescues TGF- $\beta 1$ null mice from otherwise lethal defects in vasculogenesis or early embryogenesis (15), but this background is reported not to rescue the endoglin null phenotype (4).

Endoglin also interacts with receptor complexes associated with signaling by activins and bone morphogenetic proteins (BMPs) $(18,21)$. Similarities in the vascular phenotypes of mice deficient in endoglin, SMAD5 (22) (a cytoplas- mic signaling moiety implicated in activin and BMP signaling), and ALK-1 (cited in ref. 21) will no doubt fuel debate as to which endoglin interactions are of functional importance, at least for the development of the embryonic vasculature and heart, and for HHT itself.

However, to fully account for the discrepancies between the carefully observed endoglin heterozygotes on similar 129/Ola backgrounds (1, 4; Table 1), we probably need to consider additional genetic and environmental precipitants of the full phenotype. How reminiscent this is of discussions regarding HHT patients $(13,14)$ ! Their model has arrived.

\section{Acknowledgments}

C.L. Shovlin is supported by the Wellcome Trust.

1. Bourdeau, A., Dumont, D.J., and Letarte, M. 1999. A murine model of hereditary hemorrhagic telangiectasia. J. Clin. Invest. 104:1343-1351.

2. Li, D.Y., et al. 1999. Defective angiogenesis in mice lacking endoglin. Science. 284:1534-1537.

3. Drake, C.J., Hungerford, J.E., and Little, C.D. 1998. Morphogenesis of the first blood vessels. Ann. NY Acad. Sci. 857:155-179.

4. Arthur, H.M., et al. 1999. Endoglin, an ancillary TGF $\beta$ receptor, is required for extra-embryonic angiogenesis and plays a key role in heart development. Dev. Biol. In press.

5. Heldin, C.-H., Miyazono, K., and ten Dijke, P. 1997. TGF- $\beta$ signalling from cell membrane to nucleus through SMAD proteins. Nature. 390:465-471.

6. Pepper, M.S. 1997. Transforming growth factorbeta: vasculogenesis, angiogenesis and vessel wall integrity. Cytokine Growth Factor Rev. 8:21-43.

7. McAllister, K.A., et al. 1994. Endoglin, a TGF- $\beta$ binding protein of endothelial cells, is the gene for hereditary haemorrhagic telangiectasia type 1. Nat. Genet. 8:345-351.

8. Shovlin, C.L., Hughes, J.M.B., Scott, J., Seidman, C.E., and Seidman, J.G. 1997. Characterization of endoglin and identification of novel muta- tions in hereditary hemorrhagic telangiectasia. Am. J. Hum. Genet. 61:68-79.

9. Pece, N., et al. 1997. Mutant endoglin in Hereditary Hemorrhagic Telangiectasia type I is transiently expressed intracellularly and is not a dominant negative. J. Clin. Invest. 100:2568-2579.

10. Johnson, D.W., et al. 1996. Mutations in the activin receptor-like kinase 1 gene in hereditary haemorrhagic telangiectasia type 2. Nat. Genet. 13:189-195.

11. Piantanida, M., et al. 1996. Hereditary haemorrhagic telangiectasia with extensive liver involvement is not caused by either HHT1 or HHT2.J. Med. Genet. 33:441-443.

12. Plauchu, H., de Chadarévian, J.-P., Bideau, A., and Robert, J.-M. 1989. Age-related profile of hereditary hemorrhagic telangiectasia in an epidemiologically recruited population. Am. J. Med. Genet. 32:291-297.

13. Guttmacher, A.E., Marchuk, D.A., and White, R.I. 1995. Hereditary hemorrhagic telangiectasia. N. Engl. J. Med. 333:918-924.

14. Shovlin, C.L., and Letarte, M. 1999. Hereditary Haemorrhagic Telangiectasia and pulmonary arteriovenous malformations: issues in clinical management and review of pathogenic mechanisms. Thorax. 54:714-729.

15. Bonyadi, M., et al. 1997. Mapping of a major genetic modifier of embryonic lethality in TGF $\beta 1$ knockout mice. Nat. Genet. 15:207-211.

16. Kallapur, S., Ormsby, I., and Doetschman, T. 1999. Strain dependency of TGF $\beta 1$ function during embryogenesis. Mol. Reprod. Dev. 52:341-349.

17. Letamandía, A., et al. 1998. Role of endoglin in cellular responses to transforming growth factor- $\beta$. J. Biol. Chem. 273:33011-33019.

18. Barbara, N.P., Wrana, J.L., and Letarte, M. 1999. Endoglin is an accessory protein that interacts with the signaling receptor complex of multiple members of the transforming growth factor- $\beta$ superfamily. J. Biol. Chem. 274:584-594.

19. Dickson, M.C., et al. 1995. Defective haematopoiesis and vasculogenesis in transforming growth factor- $\beta 1$ knock out mice. Development. 121:1845-1854.

20. Oshima, M., Oshima, H., and Taketo, M.M. 1996. TGF- $\beta$ receptor type II deficiency results in defects of yolk sac hematopoiesis and vasculogenesis. Dev. Biol. 179:297-302.

21. Lux, A., Attisano, L., and Marchuk, D.A. 1999. Assignment of transforming growth factor $\beta 1$ and $\beta 3$ and a third new ligand to the type I receptor ALK-1. J. Biol. Chem. 274:9984-9992.

22. Yang, X., et al. 1999. Angiogenesis defects and mesenchymal apoptosis in mice lacking SMAD5. Development. 126:1571-1580. 